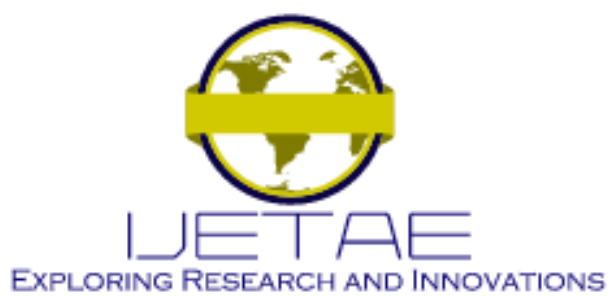

International Journal of Emerging Technology and Advanced Engineering

Website: www.ijetae.com (E-ISSN 2250-2459, Scopus Indexed, ISO 9001:2008 Certified Journal, Volume 12, Issue 01, January 2022)

Manuscript Received: 02 December 2021, Received in Revised form: 04 January 2022, Accepted: 10 January 2022

DOI: 10.46338/ijetae0122_01

\title{
Design of a Monitoring System for the identification of Gas Concentration in the district of Mi Perú - Callao, Perú
}

\author{
Jeffry Ricaldi-Cerdan $^{1}$, Brian Meneses-Claudio ${ }^{2}$, Alexi Delgado ${ }^{3}$ \\ ${ }^{1,2}$ Universidad de Ciencias y Humanidades \& Av. Universitaria 5175, Los Olivos 15304 \\ ${ }^{3}$ Pontificia Universidad Católica del Perú \& Av. Universitaria 1801, San Miguel 15088
}

\begin{abstract}
In recent years, the contamination of toxic gases in society is a very controversial problem because of the various consequences and effects they generate on health. There are several studies which highlight that the main polluting gases to the environment such as carbon monoxide, lead, cadmium, among others are the main causes of the increase in various acute diseases, such as pneumonia, or chronic diseases, such as cardiovascular diseases or lung cancer. That is why, faced with this problem, this research work proposes a monitoring system that determines the concentration of toxic gases, in such a way that it can contribute as an informative medium which can be implemented in various focused points where high rates of pollution are concentrated. The system has a very efficient MQ 135 gas sensor which includes a reading of 5 to $600 \mathrm{ppm}$ (parts per million) at $3 \mathrm{~m}$ with a temperature of $25^{\circ} \mathrm{C}$. It should be noted that it is important to keep the sensor on 24 hours beforehand to obtain a correct reading. Thus, concluding that this system of toxic gases can be easily applied to society because it is economical and because it has a free software which will be responsible for informing through a web server the level of ppm that you want to analyze at a certain point.
\end{abstract}

Keywords-- Toxic Gases, Pollution, Gas Sensor, Environment, Air Quality, co2.

\section{INTRODUCTION}

A study conducted by the Institute of Health Metrics and Evaluation has estimated that, in 2017, lead exposure has caused 1.06 million deaths and the loss of 24.4 million years of life lost due to disability due to its long-term health effects. The heaviest burden is found in low- and middleincome countries [1]. In addition, that Institution indicated that, in mid-2016, the circulation of lead represented $63.2 \%$ of idiopathic cases of insufficient intellectual development, as well as $10.3 \%, 5.6 \%$ and $6.2 \%$ of diseases, respectively, global hypertension, ischemic heart disease and stroker.
In addition, more than a third of children in third world countries have been affected by elevated levels of lead. [2]

In Peru, pollution is one of the most important environmental problems facing the country. It occurs when an imbalance occurs, after the addition of any substance to the medium, due to different processes of human production [1]. The Ministry of Health (MINSA) in a 2018 ministerial decision stated that 4,867 people in the country were affected by toxic metals. Already for 2017 our country 8.85 environmental liabilities for mining sectors and 3.5 for hydrocarbon extraction which were included in the inventory of the Ministry of Energy and Mine (MINEM). Therefore, through a ministerial resolution, MINSA created the National Health Strategy to draw the attention of those affected by pollution by heavy metals and other chemical substances through the ministerial resolution. No. 425 -2008-MINSA [3].

If we focus on the district of Mi Perú - Callao. The presenceof industrial plants with activities related to the smelting of non-ferrous metals, battery production, chemical production, and other inputs. They have affected the quality of the environment, seriously endangering the health of the surrounding communities, especially children, the elderly and pregnant women [4]. To this end, the Regional Health Directorate of Callao (DIRESA) notified the Ombudsman's Office of the implementation of the activities planned as part of the Intervention Plan to draw the attention of people exposed to heavy metal contamination in the human facilities of the districts of $\mathrm{Mi}$ Perú and Ventanilla, within the framework of which samples were taken from 110 children, almost $50 \%$ of students, of which only 10 exceeded the allowed limit. But in the same way lead was found in the blood, reporting cases of up to 22.2 micrograms of lead, that is, $124 \%$ according to the parameters of the MINSA guidelines [5]. 


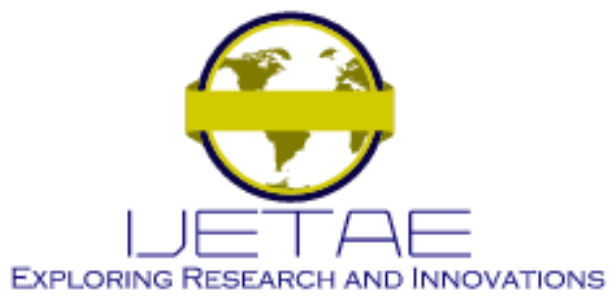

International Journal of Emerging Technology and Advanced Engineering Website: www.ijetae.com (E-ISSN 2250-2459, Scopus Indexed, ISO 9001:2008 Certified Journal, Volume 12, Issue 01, January 2022)

Thus, at present there are technological platforms of climatological information that offer information of main localities, however, the development of an implementation model of environmental climatological monitoring based on the use of free resources in environmental matters for obtaining data in real time and in places where a meteorological station is not installed [6] is not counted as an alternative.

In this work, he aims to build a software implementation model of a weather station that allows recording environmental values such as temperature, humidity, air quality index and ultraviolet radiation thanks to climate sensors. This system is included as a main component of the Raspberry platform included with Arduino UNO that acts as a processor of the information received from intelligent sensors, to send the received data to an external storage service and perform queries via the Internet. After the proposal, the results obtained by the implemented meteorological station are shown, which considered two localities such as Arequipa and Moquegua, allowing to obtain the detection values corresponding to the variables of temperature (0 to $50 \mathrm{C}^{\mathrm{o}}+/-2 \%$ precision), humidity (20 to $80 \%$ with $+/-4 \%$ precision), ultra violet radiation (280 to $390 \mathrm{~nm}+/-1 \mathrm{UV}$ ) and air quality index (10 to 1000ppm or parts per million) $+/-3.35$ accuracy) according to the minimum and maximum values. Therefore, it is concluded that Arduino technology is very efficient due to its wide compatibility with operating systems for its application, thanks to which the optimization of resources and costs is conducted, as well as its application. With Raspberry Pi as the processing center to finally be sent to a remote server, the values obtained were satisfactorily analyzed by evaluating them with the web [7].

The objective of the research work is to design a gas monitoring system to determine the concentration of lead in the air in the various strategic points of the district of $\mathrm{Mi}$ Perú. That data will be viewed through an Android application which will be accessible to users in general. This project is of utmost importance since it will locate the level of lead concentration in the most concurrent points of the population, which will be transmitted through an LED panel generating an alert of the level of contamination of that area. Finally, this project will help us to apply various comparisons with studies that lead us to contribute to the most optimal monitoring.

Wireless control systems have revolutionized today as it facilitates communication in spaces where using wired materials would be a problem depending on the area where it is applied [11].
That is why the ESP 8266 module unlike other platforms can connect to a Wifi network allowing wireless connection to a local network or the Internet being compatible with the IEEE $802.11 \mathrm{~b} / \mathrm{g} / \mathrm{n}$ standard. In addition, this module is being widely applied in various control projects, automation as well as oriented to the applications of IoT technology [12].

Arduino is another platform that has revolutionized technology education. It is a device that has several versions and models.

It includes an ATMEL microcontroller that allows you to create diverse types of microcomputers, allowing you to easily establish connections with various sensors, actuators, and electronics thanks to free software [13].

The present work is structured as follows, in section II which is the methodology will explain the design of the devices to be used in the installation, operation and advantage of the gas analyzer. In section III the results obtained will be evidenced, in section IV the methodology and results of the proposed background will be discussed. Finally, section V will visualize the conclusions, as well as recommendations of the research work.

\section{LITERATURE REVIEW}

In [8] he mentions that a third of the population, i.e., $75 \%$, considers air pollution to be one of the most serious problems in the country. Among all air pollutants, health effects are determined as soon as nitrogen dioxide (NO2), sulfur dioxide (SO2), carbon monoxide (CO), tropical floor floors (O3), and volatile organic compounds (VOCs) and $\mathrm{CO} 2$ (carbon dioxide). The purpose of that research work included the design and implementation of a basic gas analyzer for vehicles made up of carbon dioxide (CO2), carbon monoxide (CO) and volatile organic compounds (VOCs) sensors. This analyzer includes gas sensors, a data acquisition card such as Waspmote, which interprets the values measured by the sensor and transmits them via WIFI protocol to a mobile device with Android operating system. Likewise, various monitoring and operation tests were conducted in a controlled environment, with a duration of 20 minutes, the demonstration test consisted of the activation of the devices, as well as a WIFI transmitter. From this, the results obtained from the implementation process infer that the system is working properly, presenting drastic changes in co and VOC concentrations with an initial value of $50 \mathrm{ppm}$ that can vary $600 \mathrm{ppm}$ due to the combustion of a vehicle. 


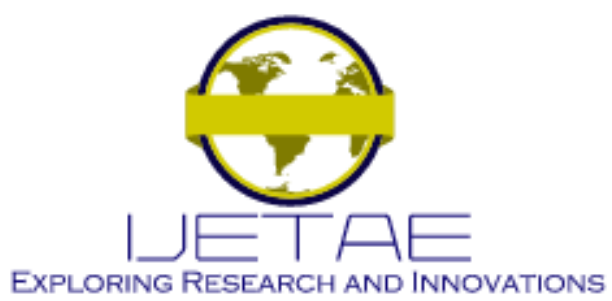

International Journal of Emerging Technology and Advanced Engineering Website: www.ijetae.com (E-ISSN 2250-2459, Scopus Indexed, ISO 9001:2008 Certified Journal, Volume 12, Issue 01, January 2022)

Finally, it is concluded that the innovative basic portable gas analyzers are dependable, stable, and reproducible since they measure each polluting variable to which we humans are exposed daily, without awareness of it and the great environmental impact [9].

Similarly, you can find various sources of pollutant in transport which can be cars, buses, trains, airplanes, helicopters, etc. If you focus it is known that cars produce mostly dangerous polluting gases [8]. For this reason, an implementation of a toxic gas monitoring system is proposed, which will be controlled by an Arduino platform, which can record data and processing them through an application which is of low cost its installation.

That system works with the Arduino Atmega 2560 platform as the main component, it also uses a NetBeans program to export gas sensor data from the Arduino to Excel, also the Java software is of utmost importance since it has an exclusive library for the Arduino that allows communication between both through the serial port. As a result, it was obtained that the readings of the sensors towards the Arduino platform will depend a lot on the low or high accuracy it must detect certain ranges such as the sensors applied in that project which are MQ 4 (200 10000ppm), MQ7 (20 -2000ppm) and MQ135 (10$1000 \mathrm{ppm})$. Finally, it is concluded that this project, unlike the traditional ones, is economical and accessible since they use commercial devices in the electronics industry [10].

\section{Methodology}

In this section it will be a proposal that we will typify according to the different areas of interest. Which develops each part of the segmentation of the design of a gas monitoring system for the determination of lead concentration. All the steps mentioned are shown in the flowchart in Figure 1.

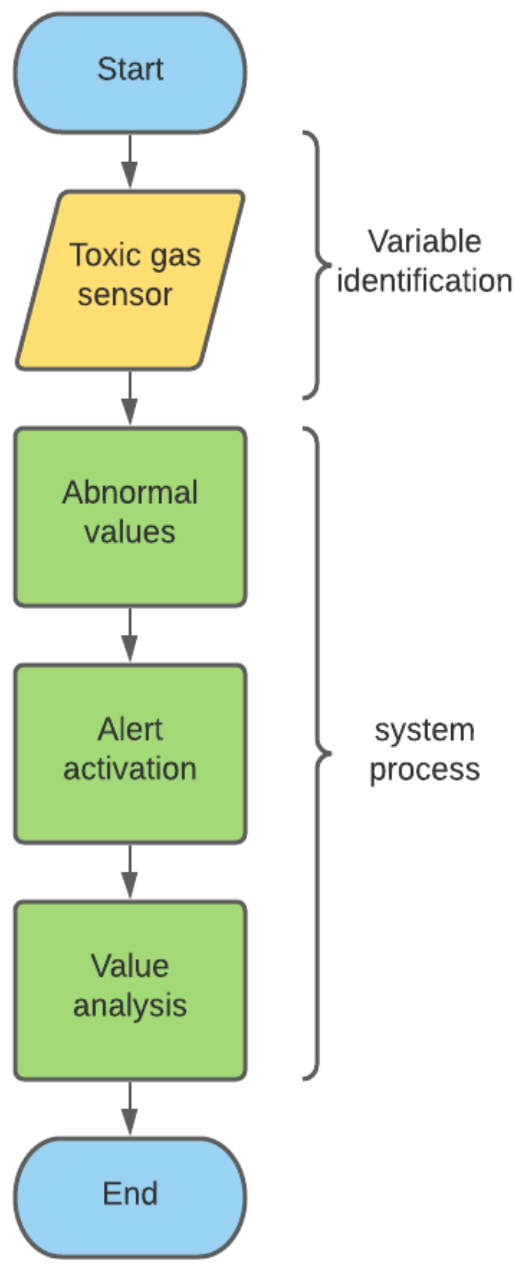

Fig. 1. Flowchart for the detection of lead contaminant gases. 


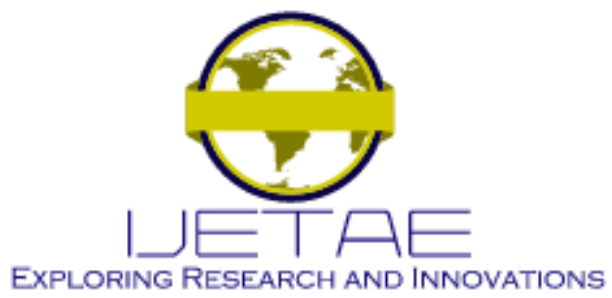

International Journal of Emerging Technology and Advanced Engineering Website: www.ijetae.com (E-ISSN 2250-2459, Scopus Indexed, ISO 9001:2008 Certified Journal, Volume 12, Issue 01, January 2022)

\section{A. Variable identification.}

Atthis stage of gas detection, an MQ 135 sensor shown in Figure 2 was used, which will describe the characteristics. The device is mostly used for the detection of the following gases such as benzene, alcohol, ammonia and among other toxic gases [14]. Those characteristics that this sensor has led to conduct various projects related to the monitoring or warning of the presence of polluting gases in the environment. It should be noted that this device is applied in control circuits such as alarms in homes or places where elevated levels of pollution must be avoided. Also, the sensor detects ranges of parts per million from 10 to 1000 which below shows the levels it detects in some gases [15].

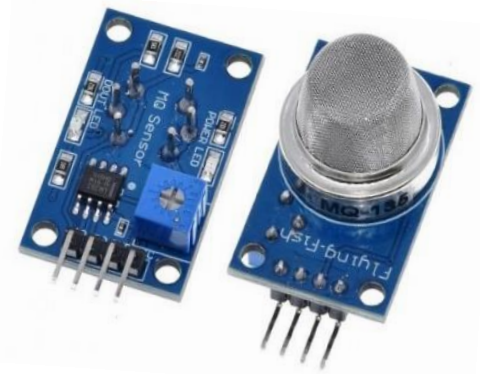

Fig 2 MQ 135 sensor.

TABLE I

MQ135 Sensor Feature

\begin{tabular}{|l|l|}
\hline \multicolumn{2}{|c|}{ Sensor model: MQ 135 } \\
\hline Operating voltage & 5VDC \\
\hline Operating current & $150 \mathrm{~mA}$ \\
\hline Operating temperature & $-20^{\circ} \mathrm{C} \sim 70^{\circ} \mathrm{C}$ \\
\hline Ppm detection & $10 \mathrm{ppm} 1000 \mathrm{ppm}$ \\
\hline $\begin{array}{l}\text { Ammonia (NH3) analysis } \\
\text { level }\end{array}$ & $\begin{array}{l}10 \text { to } 300 \text { parts per million } \\
\text { (ppm). }\end{array}$ \\
\hline $\begin{array}{l}\text { Benzene analysis level } \\
\text { (C6H6) }\end{array}$ & 10 to $1000 \mathrm{ppm}$ \\
\hline $\begin{array}{l}\text { Alcohol Analysis Level } \\
\text { (C2H5OH) }\end{array}$ & 10 to $300 \mathrm{ppm}$ \\
\hline \begin{tabular}{l} 
Operating humidity \\
\hline
\end{tabular} & $<95 \% \mathrm{RH}$ \\
\hline
\end{tabular}




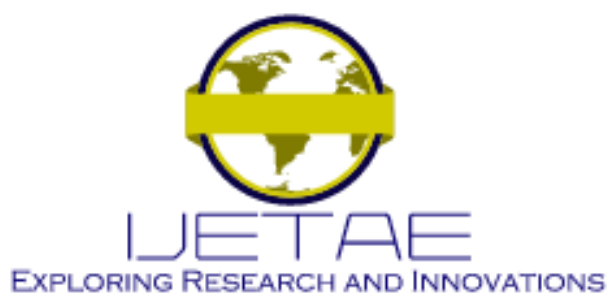

International Journal of Emerging Technology and Advanced Engineering

Website: www.ijetae.com (E-ISSN 2250-2459, Scopus Indexed, ISO 9001:2008 Certified Journal, Volume 12, Issue 01, January 2022)

Si turns on the green light as in Fig 4 indicates that the system is activated and ready to operate, but if it is in red light as Fig 5 the system indicates that it is inoperative or deactivated. This type of operation will help us to have greater control for the subsequent preventive and corrective maintenance that will be conducted on the system. After knowing the operation of the LEDs, it is also important to know the function that the siren will fulfill, which will be activated when the ppm index is at an unhealthy level as shown in fig 8 .

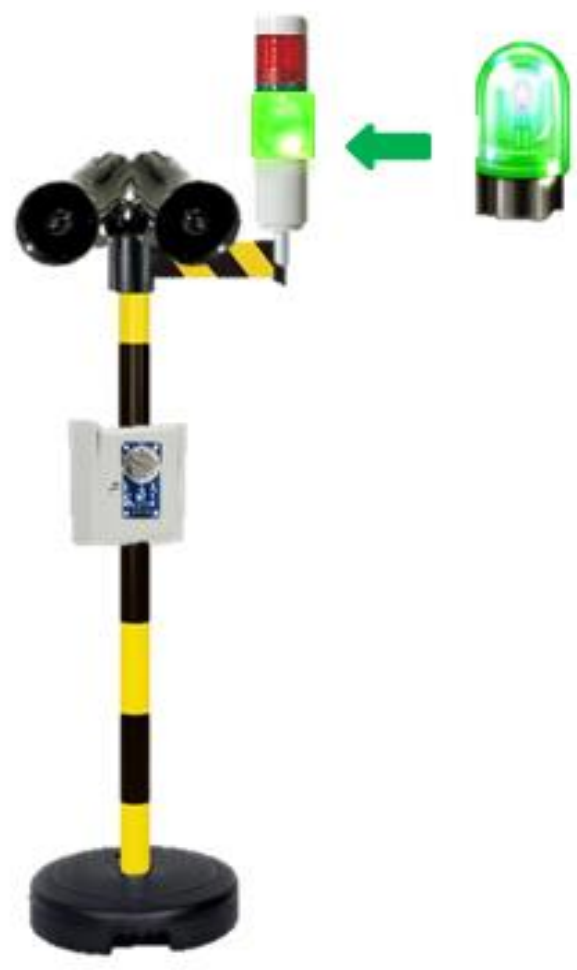

Fig. 5 Activation of the MQ-135 sensor

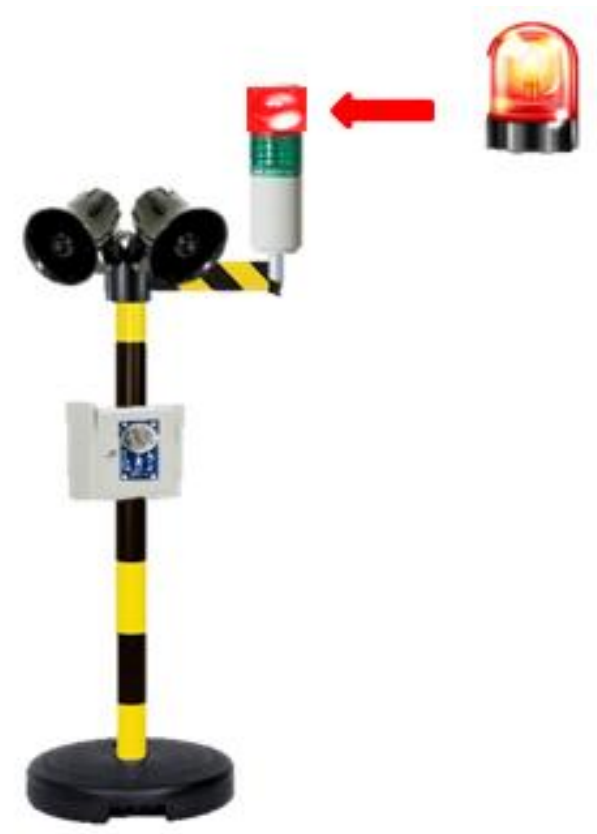

Fig 6 Disabling the MQ-135 sensor

In the second point we will focus on the mq135 sensor that is responsible for collecting environmental data and processing them to the Arduino. For this it is necessary that the module is within a range of scope to have a greater reading of the environment to be monitored. It is estimated that the sensor can give a reading at $20 \mathrm{~m}$ which can be visualized in Fig 6. In addition, the sensor will be configured to detect certain ranges of gases such as lead, ammonia, benzene which can be displayed in TABLE 1 .

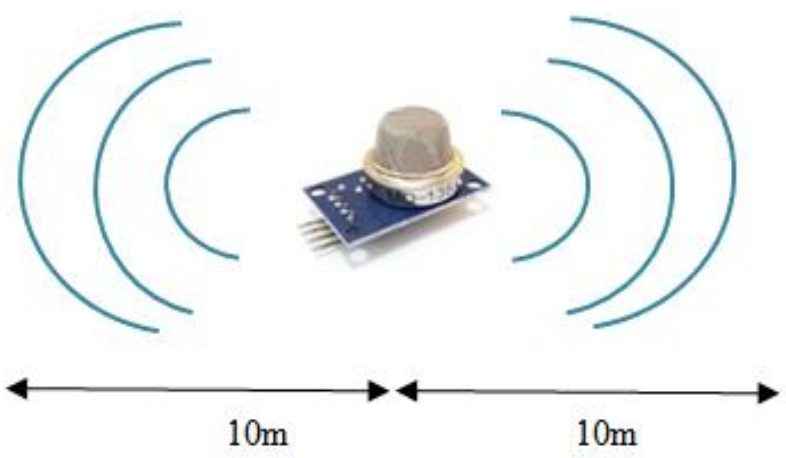

Fig 7 MQ-135 sensor reading distance 


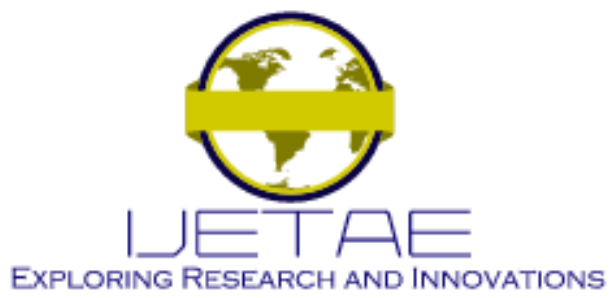

International Journal of Emerging Technology and Advanced Engineering

Website: www.ijetae.com (E-ISSN 2250-2459, Scopus Indexed, ISO 9001:2008 Certified Journal, Volume 12, Issue 01, January 2022)

Already knowing the function that the MQ 135 sensor will fulfill. an important module for the system which is the ESP 8266 which is shown in Fig 7. Its function is to send the data inalámbricamente ofl Arduino to a web server where the reading of the MQ 135 sensor is displayed.

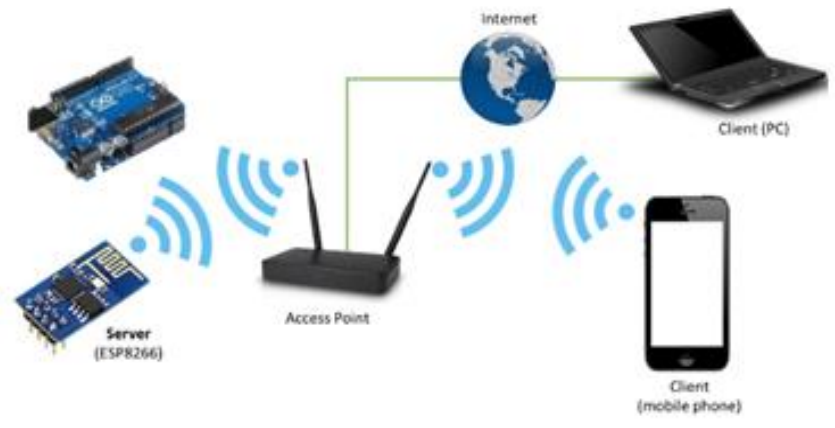

Fig. 8 Operation of esp. 8266

For the reception of the data, a web system was developed where the various values captured by the mq 135 sensor will be displayed. That system will be divided into 4 levels (well, moderate, unhealthy, and very unhealthy). In addition, as can be seen in Fig 9 each level is independently classified with its ppm reader which are derived in certain ranges that will be explained below.

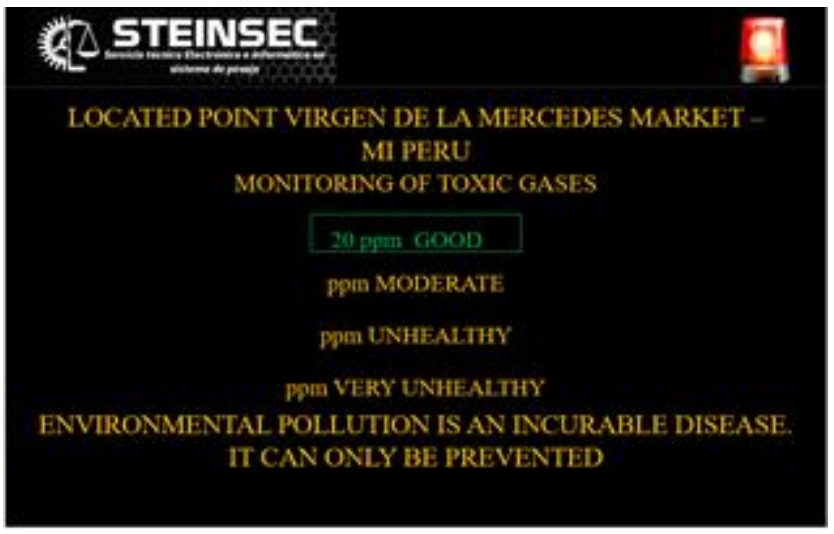

Fig. 9 Application of toxic gas monitors.

○ Good: Everyone can do activities at that point since the ppm level is extremely low. (10-50ppm)

○ Moderate: Older people, pregnant women, lung diseases, children should reduce activities at a certain point evaluated. (50ppm -100ppm)

$\circ$ Unhealthy - people dis of the moderate state should beprevented from circulating at that point. (100ppm 300ppm)
- Very unhealthy: sensitive groups of the moderate as the public should avoid being at that point. (300 1000ppm).

In addition, the proposed gas monitoring system is estimated to be raised in strategic points where the circulation of people is frequent such as recreation park, markets among other places shown in Figure 10 and 11. The purpose of installing at strategic points is to capture the most appropriate values of the anomalous gases of the air in certain areas which will be displayed the said values in an application that is shown in Fig. 9

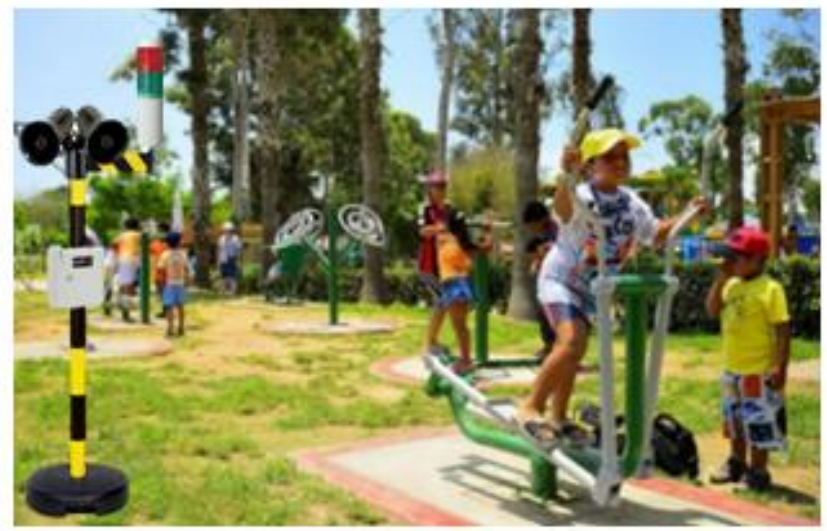

Fig. 10 Monitoring system in Recreation Park.

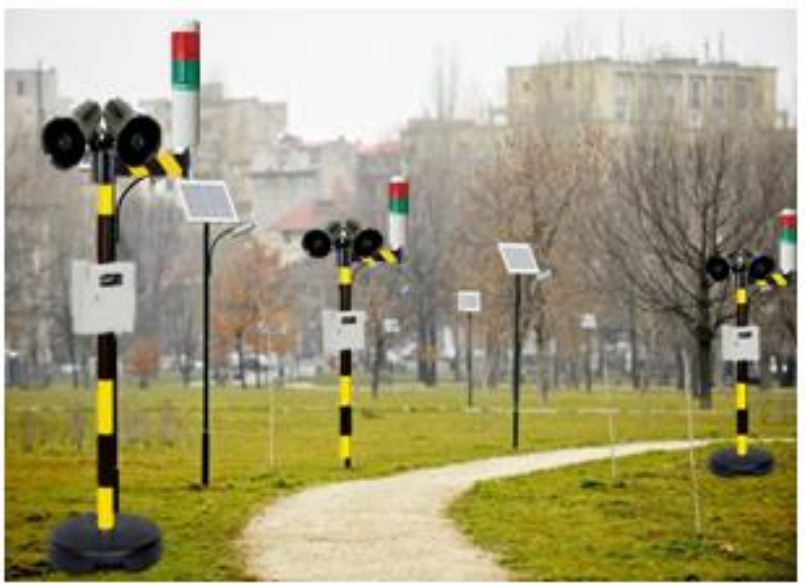

Fig. 11 Monitoring system in a city park in winter or autumn season.

Finally, fig. 12 shows the connection of the various simulated devices on the proteusplatform. In addition, some small adjustments were made to later perform the physical conditioning. 


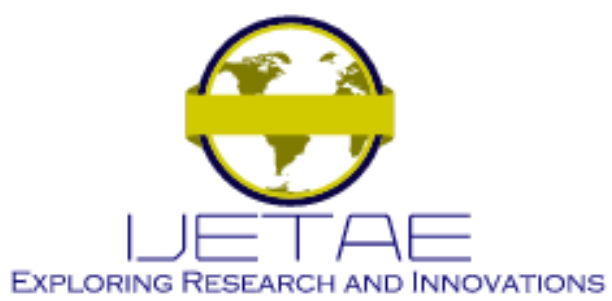

International Journal of Emerging Technology and Advanced Engineering

Website: www.ijetae.com (E-ISSN 2250-2459, Scopus Indexed, ISO 9001:2008 Certified Journal, Volume 12, Issue 01, January 2022)

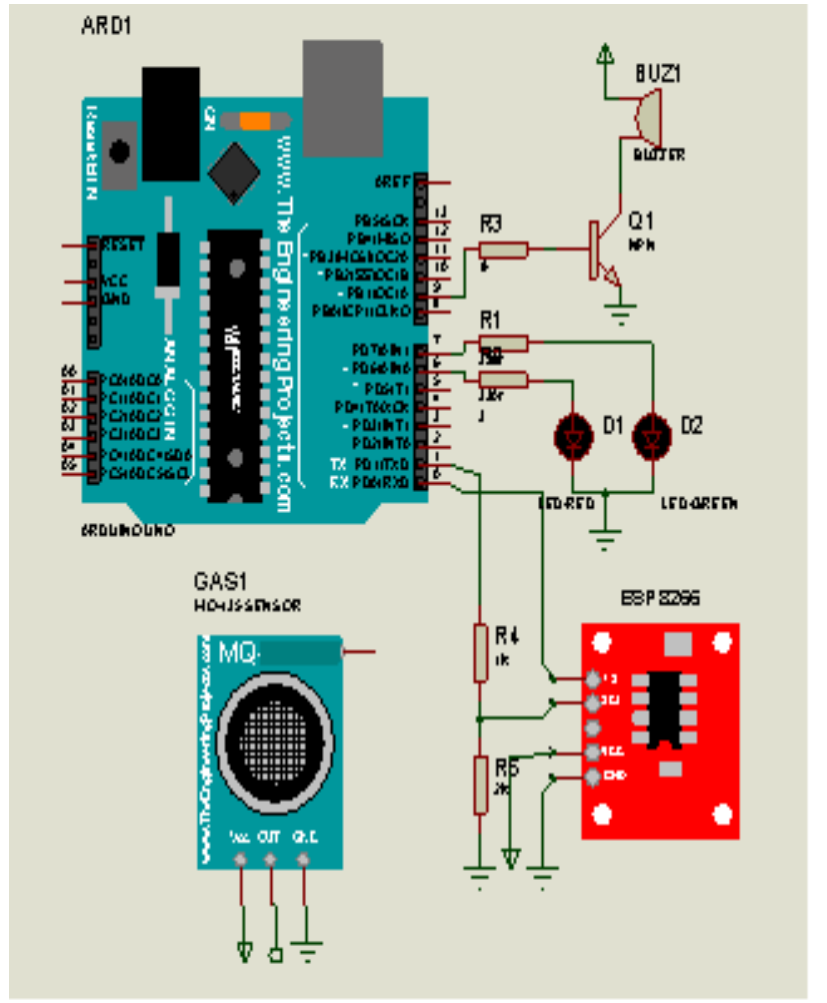

Fig. 12 Simulation of the Gas Monitoring System.

\section{RESULTS}

At that stage, mention is made of the specific results obtained in the implementation process. Which proceeded to make the various comparisons of real values of the devices that make up the system. This physical simulation system can be visualized in Fig. 13.

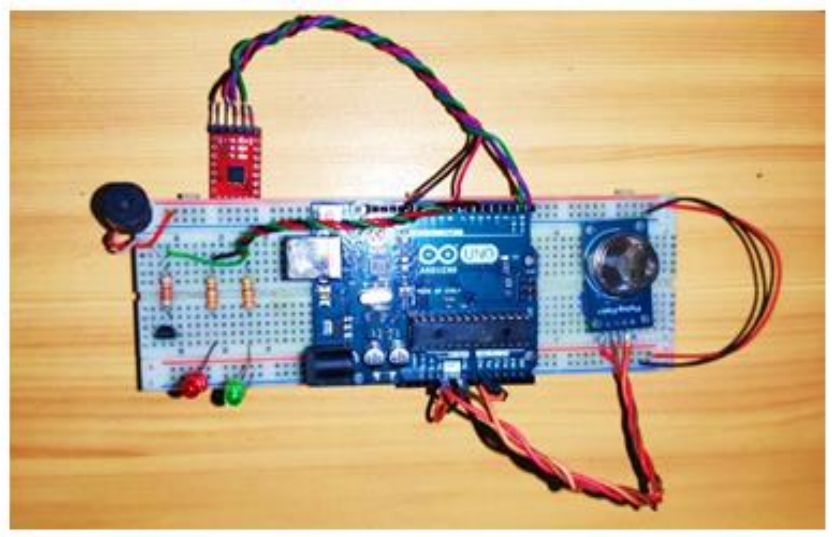

Fig. 13 Gas Monitoring System Hardware
After observing the implementation of the hardware of that system, we proceeded to perform the various tests which generated positive results that can be seen in Table 2 .

TABLE II.

Resulting table

\begin{tabular}{|c|c|}
\hline Gas monitoring system. & Results \\
\hline Recommended operating time. & $12 \mathrm{~h}$ \\
\hline $\begin{array}{c}\text { Temperature operated in the } \\
\text { simulation }\end{array}$ & $25^{\circ} \mathrm{C}$ \\
\hline $\begin{array}{c}\text { Supply voltage to the circuit } \\
\text { mq 135 sensor reading range }\end{array}$ & $5 \mathrm{VDC}-1 \mathrm{~A}$ \\
\hline $\begin{array}{c}\text { minimum and maximum } \\
\text { sensor reading (ppm) }\end{array}$ & $5 \mathrm{ppm}-600 \mathrm{ppm}$ \\
\hline $\begin{array}{c}\text { Green light on } \\
\text { Red light on }\end{array}$ & $5 \mathrm{ppm}-100 \mathrm{ppm}$ \\
\hline $\begin{array}{c}\text { operating range of the esp. } \\
\text { 8266 modules }\end{array}$ & 7 meters \\
\hline
\end{tabular}

It was also verified that the alert levels operate correctly. To do this before starting the tests had to keep the system on for an approximate of $12 \mathrm{~h}$ so that the mq 135 sensor has greater stability or a better reading, it should be noted that the manufacturer recommended $24 \mathrm{~h}$ but that decision was made since a continuous reading was seen. After that, the respective tests were conducted as shown in Fig. 14, which shows the system in operation, automatically lighting the green LED indicating a moderate or good environment.

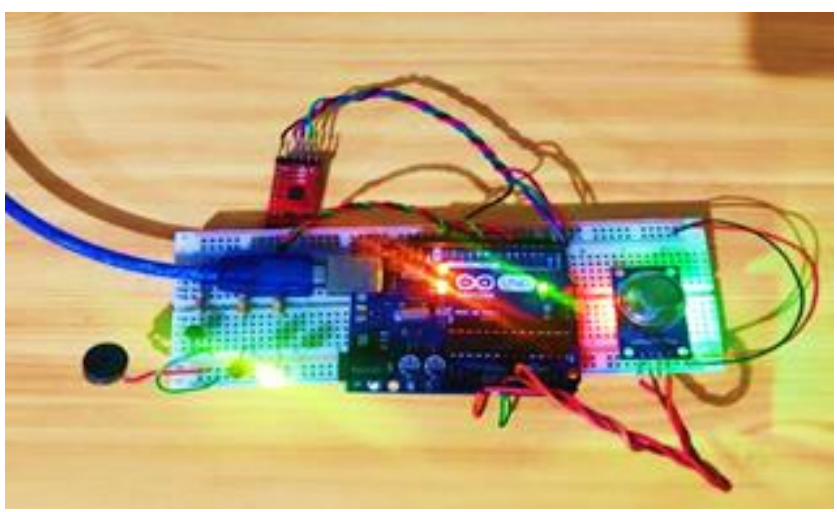

Fig. 14 Green light system at moderator satisfactory level.

The ignition the green led will indicate in the web server that it is at a level bueno in a Range of 10 to $50 \mathrm{ppm}$. This time in Fig. 15 the status and level displayed is 30 ppm. 


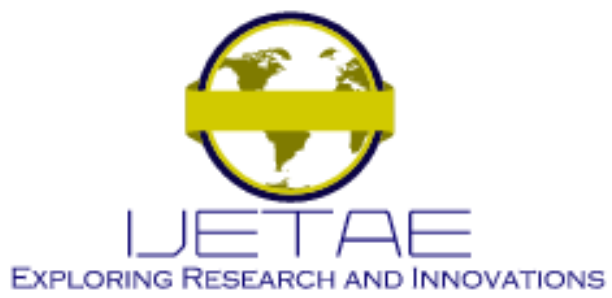

International Journal of Emerging Technology and Advanced Engineering

Website: www.ijetae.com (E-ISSN 2250-2459, Scopus Indexed, ISO 9001:2008 Certified Journal, Volume 12, Issue 01, January 2022)

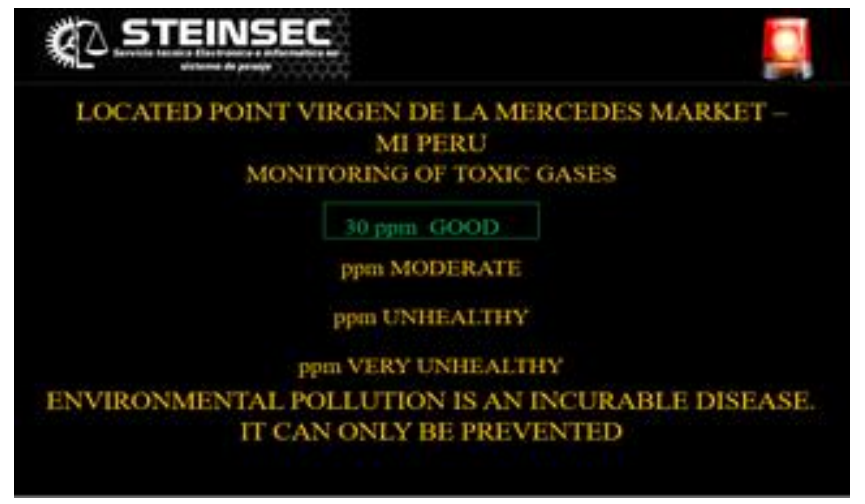

Fig. 15 System in operation at satisfactory level.

Likewise, in Fig.16 a level of $60 \mathrm{ppm}$ is observed indicating that it is in the range of 50 to $100 \mathrm{ppm}$, which means that we are at a moderate level. That means that people of legal age, pregnant women and children must have the transition of that place.

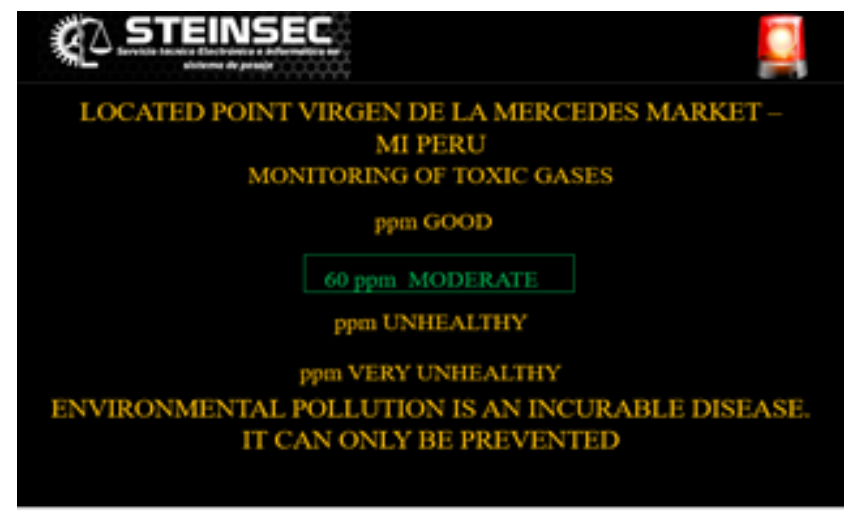

Fig. 16 System in operation at moderate level.

On the other hand, we proceeded to simulate a polluted environment by generating smoke through a lighter, which automatically turned on the red LED and activated the buzzer, thus indicating that the environment is unhealthy or very unhealthy. This system is shown in Fig 17.

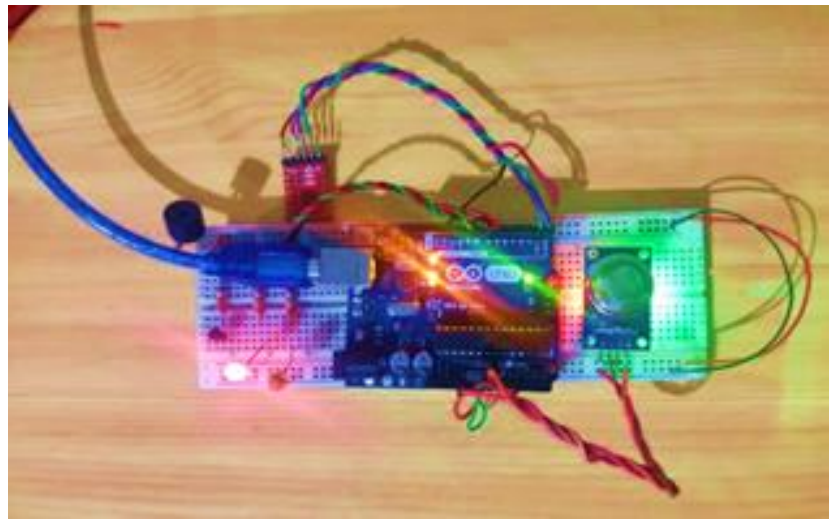

Fig. 17 Red light system at unhealthy or very unhealthy level

That alert tells us on the server that we are in a range of 100 to $300 \mathrm{ppm}$ which means that we are at an unhealthy level. In Fig. 18 it shows us a level of $130 \mathrm{ppm}$ at which people of the moderate state should be prevented from circulating at that point.

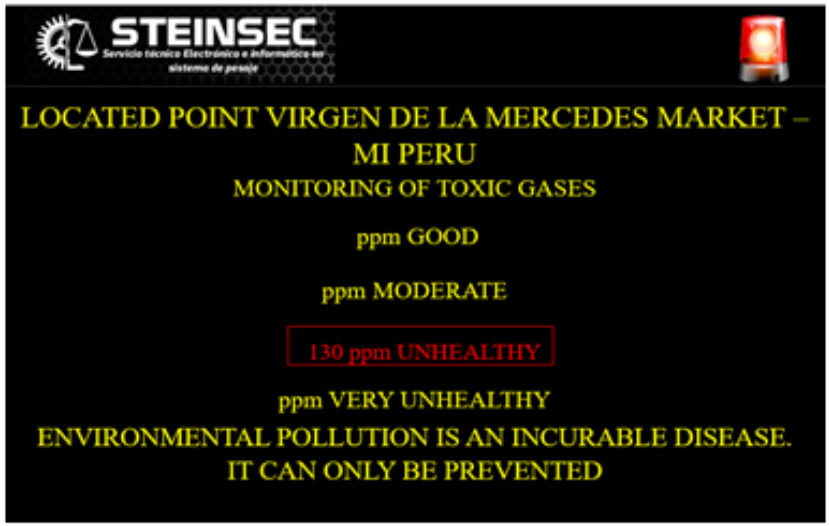

Fig. 18 System in operation at unhealthy alert level

In Fig. 19, a level of 305 ppm is observed which indicates that the environment is very unhealthy being its range of 300 to $1000 \mathrm{ppm}$. At such a level it is recommended that people circulate in a certain area. 


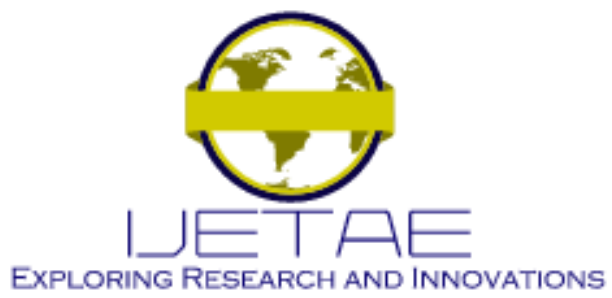

International Journal of Emerging Technology and Advanced Engineering Website: www.ijetae.com (E-ISSN 2250-2459, Scopus Indexed, ISO 9001:2008 Certified Journal, Volume 12, Issue 01, January 2022)

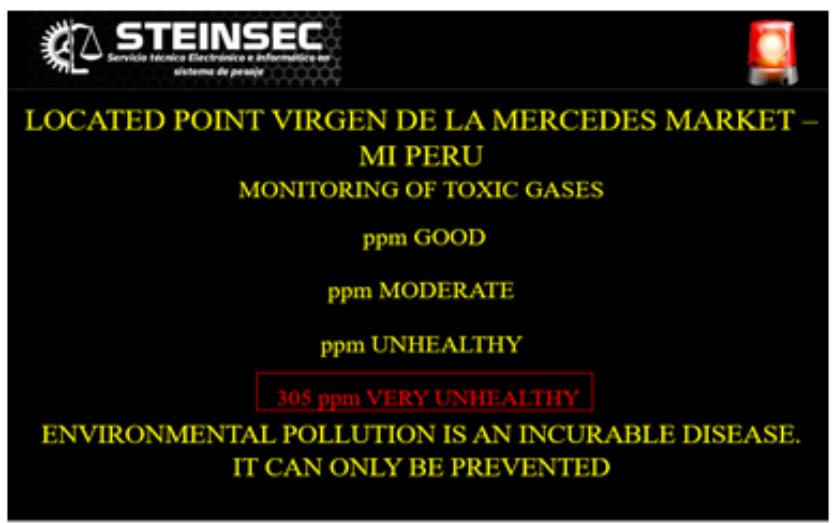

Fig. 19 System in operation at very unhealthy alert level

Finally, you can see how efficient the proposed monitoring system is since it serves as a means of real-time information from various points where toxic gases can be focused. This system reports the status level of the environment located on a web server which is accessible to any mobile device. Additionally, the web system has two LED indicators which will turn on depending on whether it is in an optimal or lousy state for it the buzzer or siren will work only when the environment is not suitable for transit.

\section{Discussions}

With respect to the results obtained, it can be visualized that when simulating with a lighter or lighter, high values were obtained that reached a very unhealthy level in a range of $305 \mathrm{ppm}$ as shown in Fig. 18. This estimate has a relationship to work [5] who performsorabasicanalyzer of gases for vehicular emissions in which I generate reading of 300 to 500ppm of $\mathrm{CO} 2$ and $\mathrm{CO}$, these values are for the different octane that was evaluated in the simulation vehicles. Thus, you can see the great similarity of the research work [5] with the one that is proposed since it verifies the great efficiency that the gas sensors of the MQ family have, it is also verified that no considerable variation was found with respect tothe type of Arduino that is used.

Another relevant point is that that sensor $\mathrm{mq} 135$ is used due to the low cost since there are sensors such as the mq-811 that its value is very high, in which the purpose of that work is to reduce costs so that it is accessible to various points of the population, also that that type of sensor reads various gases as you can see in TABLE 1 said this selection is mostly due to the research work [6] which indicates the advantage of using the mq 135 thus proposing a prototype of a $\mathrm{CO} 2$ monitoring system using free hardware.
It should be noted that this work, unlike the one proposed in that article, is that it uses a Shield data logger SD module to store the daily records of the values detected by the sensor while our work proposes to send data wirelessly through the esp8266 module to a web server and the user can see in real time said ppm values at the focused point.

Likewise, it was possible to verify the results in its 4 levels that make them up. Programmed in various ranges such as good, moderate, unhealthy, and very unhealthy which unlike the work [4] the maximum level was obtained reaching 600ppm which is shown in Table 2 . Now if we compare values, we see that in the work [4] they conducted a monitoring in the city of Arequipa which reached 100 ppm $+/-3.35$ in temperature from $20^{\circ} \mathrm{C}$ to $25^{\circ} \mathrm{C}$, while the proposed design was able to pass the $100 \mathrm{ppm}+/-3.35$ without difficulty. Lto which it is concluded that the concentration of toxic gases is concentrated mostly in the capital of Lima.

Finally, it is important to recognize that there are currently several toxic gas systems which mostly have personalized software, with various high-precision sensors which require periodic calibration which makes their value extremely high, and their price is not so accessible to citizens. That is why in that article an economic design with an educational and reliable component is proposedwhich will serve as an informative means for citizens.

\section{CONCLUSIONS}

As shown in the results, the proper functioning of the system is identified. Thus, being especially useful when detecting dangerous levels of toxic gases such as carbon dioxide, carbon monoxide, lead among other polluting gases, so its application helpsto inform citizens of the level of gas concentration in certain focused points.

Likewise, this system aims to influence more research on the consequences of lead, carbon dioxide, in various sciences, but especially in medicine and ergonomics, due to the consequences it creates for humans.

It is also essential to recognize that the educational devices applied in those designs are effective and easy to operate, as is the Arduino which is a free tool and compatible with operating systems.

Finally, it is concluded that the innovative basic portable gas analyzers are dependable, stable, and reproducible since they measure each polluting variable to which we humans are exposed daily, without awareness of it and the great environmental impact. 


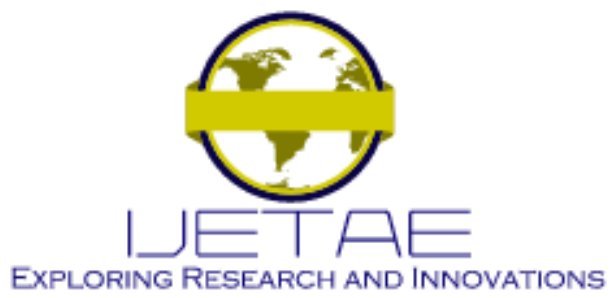

International Journal of Emerging Technology and Advanced Engineering Website: www.ijetae.com (E-ISSN 2250-2459, Scopus Indexed, ISO 9001:2008 Certified Journal, Volume 12, Issue 01, January 2022)

In addition, as work in the future, it is proposed to implement an LED matrix in which it will facilitate the citizen to visualize the level of ppm without having to have a mobile device since we know that not every population has availability to have such a device, it is also proposed to install more sensors and improve various functions on the web server.

It is recommended that when using the system, you should consider some limitations that the circuit has which are that previously you must keep on at least $12 \mathrm{~h}$ for the stabilization of the sensor. In addition, you must also work at a moderate distance since the sensor has a maximum of 10 meters of reading that according to the manufacturer indicates which unlike other modules can reach a greater distance but are more expensive. Like the sensor also the wifi module has a certain distance so that there is a good transmission .02is why it is important to visualize the datasheet of each device.

\section{REFERENCES}

[1] T. Sediments, "Air Pollution, Everyone's Problem," vol. 67, no. 2, pp. 189-191, 2019.

[2] L. Guerrero, C. Ramos, J. Silva, J. Romero, and M. Napsuciale, "Nutrition as a Pillar in the Different Stages of Life," J. Chem. Inf. Model., vol. 8, no. 5, pp. 1-70, 2019.

[3] [3] L. Bianchini, Flavian; Grassi, "Biomonitoring of Metals in Children of the Populated Center of Paragsha Cerro de Pasco Peru," p. 31, 2018,

[4] N. Y. Villacorta, "'Determination of lead levels in adult settlers of the Human Settlement "Virgen de Guadalupe", Mi Perú district, of the Constitutional Province of Callao,"' Medicine (B. Aires)., pp. 1105, 2018.

[5] M. Perez, "Knowledge of Mothers on Lead Contamination in Children Aged 3 to 5 Years of The I.E.I. Immaculate Virgin of Guadalupe No 141 - My Peru, 2018," Univ. César Vallejo, p. 61, 2018.

[6] J.C. Martínez Zarate and O. A. Durango Román, "Real-time carbon monoxide monitoring system in the home as an application of the internet of things," Rev. CINTEX, vol. 24, no. 2, pp. 25-32, 2019, doi: 10.33131/24222208.335.
[7] G. Irani, "Implementation Model for Monitoring and Control of Environmental Conditions Based on Arduino and Raspberry Technologies," Univ. San Agustín -Arequipa, 2021.

[8] A. García Ruíz, "Evaluation of the concentration of $\mathrm{CO}, \mathrm{NO} 2$ and SO2 in the air by vehicular traffic in the district of Morales, 2018," Univ. Peru. Union, no. 2, pp. 1-95, 2019.

[9] J. J.M.M, A. Gutiérrez, M. Pablo, and M. Arturo, "Diseño e implementación de un analyzer básico de gases para emisiones vehiculares ( $\mathrm{HC}, \mathrm{CO}$ y $\mathrm{CO} 2$ ), developed under the platform android Design and implementation of a basic gas analyzer for vehicle emissions ( $\mathrm{HC}, \mathrm{CO}, \mathrm{CO} 2$ ), developed under the a," Rev. Ing. and Region., vol. 15, no. 1, pp. 57-64, 2017.

[10] F. Marco Millán, "Design and implementation of a gas measurement system with Arduino," Repos. the Univ. Zaragosa, p. 122, 2017.

[11] Cong, Y., Zhang, B., Xing, Y., \& Zhu, J. (2020). Design of a portable toxic gas monitor. Proceedings of 2020 IEEE International Conference on Advances in Electrical Engineering and Computer Applications, AEECA 2020, 517-521.

[12] Rajalakskini, K., \& Vidhya, J. (2019). Toxic environment monitoring using sensors based on IoT. International Journal of Recent Technology and Engineering, 7(6), 675-681.

[13] Ma, C., Li, N., Pang, X., Wang, S., \& Yang, Y. (2018). Hardware Design of Factory Toxic Gas Leakage Monitoring System Based on CC2530. Proceedings - 2018 10th International Conference on Intelligent Human-Machine Systems and Cybernetics, IHMSC 2018, 2, 243-245.

[14] Siregar, B., Irwansyah, Seniman, \& Fahmi, F. (2019). Monitoring of Toxic Gas and Dust from Motorized Vehicles on the Highway Using Internet of Things and Blob Detection. 2019 3rd International Conference on Electrical, Telecommunication and Computer Engineering, ELTICOM 2019 - Proceedings, 70-73.

[15] Mukherjee, M., Shu, L., Hu, L., Hancke, G. P., \& Zhu, C. (2017). Sleep Scheduling in Industrial Wireless Sensor Networks for Toxic Gas Monitoring. IEEE Wireless Communications, 24(4), 106-112.

[16] Caragnano, G., Ciccia, S., Bertone, F., Varavallo, G., Terzo, O., Capello, D., \& Brajon, A. (2020). Unmanned aerial vehicle platform based on low-power components and environmental sensors: Technical description and data analysis on real-time monitoring of air pollutants. 2020 IEEE International Workshop on Metrology for AeroSpace, MetroAeroSpace 2020 - Proceedings, 550-554. 